\title{
Management of small aortic annulus in the era of sutureless valves: A comparative study among different biological options
}

Aly Ghoneim, MD, Ismail Bouhout, MD, MSc, Philippe Demers, MD, MSc, Amine Mazine, MD, MSc, Mary Francispillai, MD, Ismail El-Hamamsy, MD, PhD, Michel Carrier, MD, MBA, Yoan Lamarche, MD, MSc, and Denis Bouchard, MD, PhD

\section{ABSTRACT}

Objective: Aortic valve replacement (AVR) in patients with a small aortic annulus is a challenging problem. The objective of this study was to compare 4 surgical approaches in terms of hemodynamics and perioperative outcomes.

Methods: A retrospective single-center study included 351 consecutive patients with a small aortic annulus $(\leq 21 \mathrm{~mm})$ who underwent aortic valve surgery between January 2007 and December 2014. Surgical techniques included standard AVR in $259(74 \%)$ patients, aortic root enlargement in $20(6 \%)$, implantation of a stentless bioprosthesis in $23(6 \%)$, and sutureless AVR in 49 $(13 \%)$.

Results: Three hundred and eleven $(89 \%)$ patients were female. The mean Logistic EuroSCORE II varied significantly among the groups and ranged from $6.5 \% \pm 5.4 \%$ in the standard AVR group to $9.2 \% \pm 4.7 \%$ in the stentless group. Early mortality occurred in $26(7 \%)$ patients. Patients in the stentless group had the lowest aortic valve mean gradients on predischarge transthoracic echocardiography $(10.9 \pm 6.2 \mathrm{~mm} \mathrm{Hg} ; P<.001)$. In the stented group, the Trifecta prosthesis displayed the lowest postoperative mean transaortic gradient $(10.3 \pm 3.6 ; P<.001)$ with no severe prosthesis-patient mismatch. Postoperative gradients of the sutureless group were comparable with stented prostheses.

Conclusions: In our study, stentless AVR and Trifecta bioprostheses had the best hemodynamic outcomes. The Perceval sutureless prosthesis provides reasonable hemodynamic performance and is a safe alternative. (J Thorac Cardiovasc Surg 2016;152:1019-28)

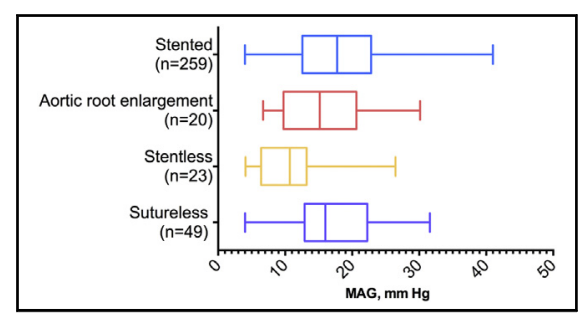

Postoperative TTE gradient distribution.

\section{Central Message}

Stentless and Trifecta prostheses give the best hemodynamics in cases of small aortic annulus. Sutureless valves are comparable with stented prostheses.

\section{Perspective}

Aortic valve replacement in patients with a small aortic annulus is a challenging problem. The present study draws attention to the hemodynamic performance of 4 management strategies (stented AVR, stentless AVR, sutureless AVR, and aortic root enlargement) that could be used in the context of a small aortic annulus $(\leq 21 \mathrm{~mm})$.

See Editorial Commentary page 1028.
Severe aortic stenosis is a lethal disease that requires mechanical relief of left ventricular outflow obstruction. ${ }^{1}$ Aortic valve replacement (AVR) is the gold standard treatment for severe symptomatic aortic stenosis. ${ }^{2}$ The aim of AVR is to decrease pressure and volume overload on the left ventricle, allowing for left ventricular mass regression. To achieve this goal, residual transvalvular gradients should be minimal. However, implantation of a small

\footnotetext{
From the Department of Cardiovascular Surgery, Montreal Heart Institute, Université de Montréal, Montreal, Quebec, Canada.

A.G. and I.B. contributed equally to this work and share co-first authorship.

Received for publication Jan 26, 2016; revisions received June 21, 2016; accepted for publication June 24, 2016

Address for reprints: Denis Bouchard, MD, PhD, 5000 Belanger St, Montréal, Quebec, Canada H1T 1C8 (E-mail: andre.denis.bouchard@gmail.com). $0022-5223 / \$ 36.00$

Copyright (c) 2016 by The American Association for Thoracic Surgery http://dx.doi.org/10.1016/j.jtcvs.2016.06.058
}

aortic valve sometimes leads to high residual gradients, despite a normally functioning prosthesis. In addition, patients with a small aortic annulus, especially those with a large body surface area, are at higher risk of prosthesispatient mismatch, which is associated with worse clinical outcomes and decreased survival.

Conventional stented valves have a sewing ring that is partially positioned within the blood flow causing relative flow obstruction, ${ }^{4}$ especially in patients with a small aortic annulus. To decrease residual gradients and left ventricular

Scanning this QR code will take you to a procedural video.

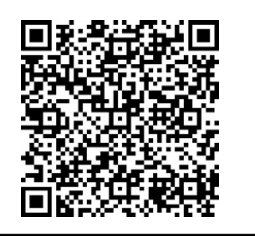




\section{Abbreviations and Acronyms \\ AVR = aortic valve replacement \\ $\mathrm{CABG}=$ coronary artery bypass graft \\ $\mathrm{CPB}=$ cardiopulmonary bypass \\ $\mathrm{EOA}=$ effective orifice area \\ $\mathrm{iEOA}=$ indexed effective orifice area \\ PPM = permanent pace maker \\ TAVI $=$ transcatheter aortic valve implantation \\ TEE $=$ transesophageal echocardiography \\ TTE $=$ transthoracic echocardiography}

outflow tract obstruction, several alternatives have been proposed, including aortic root enlargement and root replacement using a stentless bioprosthesis. However, the hemodynamic benefits of these approaches must be weighed against an increased surgical risk because of technical difficulty, prolonged periods of cardiopulmonary bypass (CPB), and myocardial ischemia. ${ }^{5}$ Recently, sutureless aortic bioprostheses have been proposed as a new solution to the problem of the small aortic annulus in elderly high-risk surgical patients. ${ }^{6}$

The purpose of this study was to compare the hemodynamic performance among the 4 management strategies (stented AVR, stentless AVR, sutureless AVR, and aortic root enlargement) in the context of a small aortic annulus $(\leq 21 \mathrm{~mm})$.

\section{METHODS}

\section{Study Population}

Between January 2007 and December 2014, 1703 patients with aortic stenosis who underwent AVR with a biological substitute in our institution were identified. Patients who received a mechanical prosthesis or who underwent a Ross procedure were excluded. In our institution, these operations are performed mainly in younger patients ( $<60$ years). These patients represent a distinct population from the cohort studied herein, as they tend to have a lower surgical risk, with a lower incidence of mortality and morbidity. A total of 351 consecutive patients with an aortic annulus of $21 \mathrm{~mm}$ or less were included. Among these, 259 (74\%) underwent standard AVR with stented aortic prosthesis, $20(6 \%)$ underwent aortic root enlargement, $23(6 \%)$ underwent implantation of a stentless bioprosthesis, and $49(13 \%)$ underwent sutureless AVR. The population flowchart is shown in Figure 1.

This observational, single-center, cohort study was approved by the local ethics committee and a waiver of consent was obtained.

\section{Data Collection and Follow-up}

Clinical data were prospectively collected in our center's Valve Clinic database. When necessary, individual chart review was performed to complete the dataset. Early postoperative outcomes were defined in accordance with the Society of Thoracic Surgeons' Guidelines for Reporting Mortality and Morbidity After Cardiac Valve Interventions. ${ }^{7}$ Operative mortality was defined as death occurring within 30 days of surgery or during the index hospitalization. Echocardiographic parameters including mean aortic gradient, peak aortic gradient, effective orifice area (EOA), and indexed EOA (iEOA) were assessed intraoperatively and before discharge. Eligibility for the study was determined on the basis of the preoperative aortic annulus diameter as assessed on intraoperative transesophageal echocardiography (TEE). All measurements were carried out by a single blinded observer. All patients underwent a predischarge transthoracic echocardiography (TTE) at an average of $4 \pm 2$ days postoperatively. Moderate and severe prosthesis-patient mismatch was defined as an iEOA between 0.60 to $0.85 \mathrm{~cm}^{2} / \mathrm{m}^{2}$ and $<0.60 \mathrm{~cm}^{2} / \mathrm{m}^{2}$, respectively. ${ }^{3}$ Body surface area was calculated using DuBois's formula. Creatinine clearance was calculated using the Cockcroft-Gault formula.

\section{Outcome Definition}

The primary study endpoint was the hemodynamic performance of each approach (mean transaortic pressure gradients, peak transaortic pressure gradients, EOA, iEOA, and incidence of moderate or severe prosthesis-patient mismatch) in postoperative TEE and in TTE at discharge.

Secondary outcomes were early postoperative adverse events. A further analysis was done to compare hemodynamic performance of various stented bioprostheses and patients with aortic annulus $<20 \mathrm{~mm}$ versus $\geq 20 \mathrm{~mm}$.

\section{Surgical Technique}

All surgical procedures were performed by 8 attending surgeons at our institution. The choice of procedure was based on individual patient characteristics and surgeon/patient preference. Aortic root replacement or enlargement was preferred in young patients, especially those who had previously undergone AVR or aortic root surgery. Sutureless prostheses have been implanted in our center since 2011. Sutureless AVR was preferred in older patients ( $>70$ years), patients with calcified aortic root or coronary ostia, and in patients undergoing minimally invasive AVR.

In the standard AVR group, the prosthesis was implanted using interrupted pledgetted mattress sutures. Both supra- and intraannular techniques were used according to the surgeon's preference. Sutureless AVR using the Perceval S prosthesis (Sorin Group, Saluggia, Italy) (Video 1) was performed using a specific delivery system. A catheter balloon was inserted and inflated to complete the prosthesis deployment. All patients undergoing stentless AVR received a complete root replacement. The same aortic root enlargement technique was performed in the 20 patients in this group as follows: the aortotomy incision is extended toward the posterior commissure between the noncoronary and the left coronary aortic cusps, passing through the aortic annulus, and carried 5 to $10 \mathrm{~mm}$ downwards where it stops at the anterior mitral leaflet annulus to avoid any postoperative impairment of mitral valve function. A patch of Dacron is then sutured to the $\mathrm{V}$-shaped defect and the aortic prosthesis is implanted.

\section{Statistical Analysis}

Continuous variables are presented as means \pm standard deviations and were compared using the Student $t$ test or the Mann-Whitney $U$ test, as appropriate. The Kruskal-Wallis test was used when more than 2 measurements were compared. Only available values were included in the analysis. Categorical variables are presented as frequency $(\%)$ and were compared using Pearson's $\chi^{2}$ test when the expected frequency count for each contingency table's cell was at least 5. Otherwise, a Fisher exact test was used. Statistical significance was set at $\alpha \leq 0.05$. Postoperative aortic gradients and aortic valvular area data were missing in less than $1 \%$ of patients. Whenever a value for a given variable was unavailable, the patient was not included in the analysis to avoid any nonresponse bias. Statistical analyses were performed using Statistical Package for Social Sciences v20 (IBM, Armonk, NY).

\section{RESULTS}

\section{Patients' Baseline Characteristics}

The patient's baseline characteristics are presented in Table 1 . The mean age differed significantly among the 


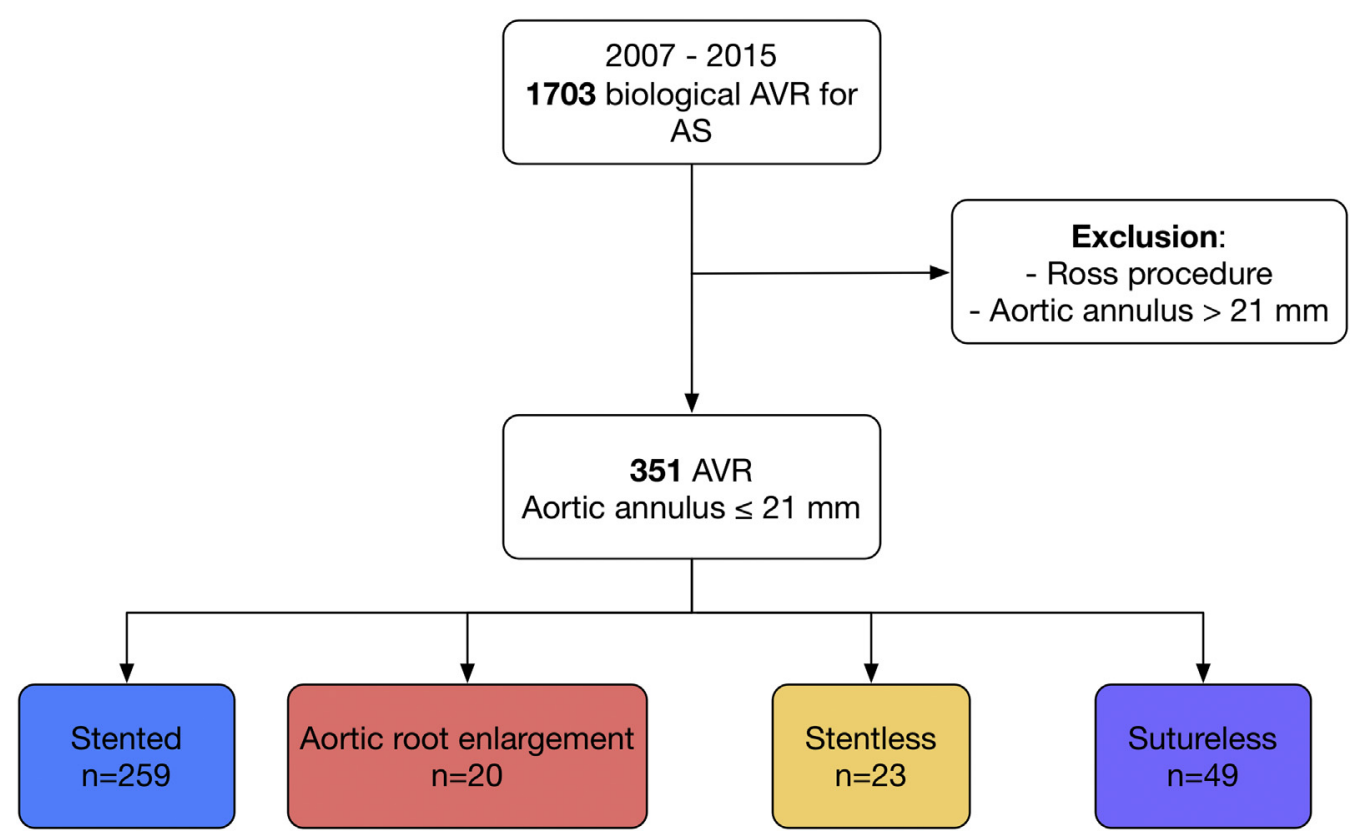

FIGURE 1. Population flow chart. $A V R$, Aortic valve replacement; $A S$, aortic stenosis.

groups; patients in the aortic root enlargement and stentless groups were younger. There was no statistically significant difference in age among patients undergoing stented or sutureless AVR. A total of 311 patients $(89 \%)$ in this cohort were female. There was no significant difference in the mean body mass index. Mean creatinine clearance was significantly higher in the aortic root enlargement and stentless groups compared with the standard AVR and sutureless groups, with no difference between the latter 2 groups $(P=.48)$. Endocarditis was the indication for surgery in 7 patients $(2 \%)$. Four patients had acute endocarditis and the remaining 3 had healed endocarditis.

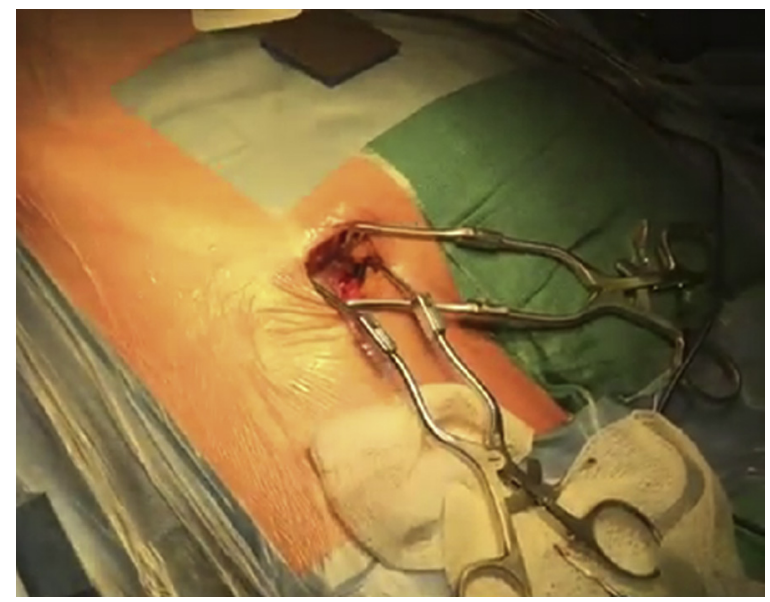

VIDEO 1. Minimally invasive aortic valve replacement using the Perceval S sutureless prosthesis via right anterior mini thoracotomy. Video available at http://www.jtcvsonline.org/article/S0022-5223(16)30851-0/addons.
None of these patients had aortic root abscesses or aortic annulus involvement. A significantly higher proportion of patients in the stentless group (26\%) had undergone previous cardiac surgery compared with patients in the aortic root enlargement $(20 \%)$, sutureless $(12 \%)$, or standard AVR $(7 \%)$ groups $(P<.001)$. In the stentless group, 6 patients $(26 \%)$ had previous cardiac surgeries. Each of these patients had previous aortic valve surgery, 4 had isolated AVR, 1 had AVR plus coronary artery bypass graft (CABG), and 1 had AVR in addition to aortic root enlargement. The mean Logistic EuroSCORE II varied significantly among the groups and ranged from $6.5 \% \pm 5.4 \%$ in the standard AVR group to $9.2 \% \pm 4.7 \%$ in the stentless group.

\section{Intraoperative Data}

Intraoperative data are presented in Table 2. Fourteen patients from the sutureless group underwent surgery through a right anterior minithoracotomy and 3 through a hemisternotomy. All other patients received a full median sternotomy. Isolated AVR was performed in 157 patients $(45 \%)$. Concomitant procedures included CABG, multiple valve procedure, septal myectomy, and Maze in $141(40 \%)$, $35(10 \%), 17(5 \%)$, and $7(2 \%)$ patients, respectively, with no statistically significant difference among the groups.

In the stented prostheses group, 19-mm and 21-mm prostheses were implanted in $156(60 \%)$ and $103(40 \%)$ patients, respectively. Fifty-eight $(22 \%)$ received CarpentierEdwards Perimount valves (Edwards Lifesciences, Irvine, Calif), 145 (56\%) received Carpentier-Edwards Perimount Magna Ease valves (Edwards Lifesciences), 23 (9\%) 
TABLE 1. Patient's baseline characteristics by procedure type

\begin{tabular}{|c|c|c|c|c|c|}
\hline Variable & Stented $(n=259)$ & $\begin{array}{c}\text { Aortic root } \\
\text { enlargement }(n=20)\end{array}$ & Stentless $(n=23)$ & Sutureless $(n=49)$ & $P$ \\
\hline Age, $\mathrm{y} \pm \mathrm{SD}$ & $74.7 \pm 7.6$ & $69.9 \pm 5.4$ & $64.8 \pm 11.6$ & $78.0 \pm 6.0$ & $<.001$ \\
\hline Female gender & $229(88)$ & $16(80)$ & $18(78)$ & $48(98)$ & .03 \\
\hline Body mass index, $\mathrm{kg} / \mathrm{m}^{2} \pm \mathrm{SD}$ & $28.3 \pm 5.9$ & $29.5 \pm 6.8$ & $29.4 \pm 7.1$ & $28.4 \pm 7.1$ & .84 \\
\hline Body surface area, $\mathrm{m}^{2} \pm \mathrm{SD}$ & $1.66 \pm 0.16$ & $1.64 \pm 0.43$ & $1.72 \pm 0.20$ & $1.62 \pm 0.14$ & .23 \\
\hline Hypertension & $213(82)$ & $13(65)$ & $19(83)$ & $44(90)$ & .22 \\
\hline Dyslipidemia & $188(73)$ & $10(50)$ & $14(61)$ & $44(90)$ & .002 \\
\hline Diabetes & $84(32)$ & $8(40)$ & $1(4)$ & $16(33)$ & .03 \\
\hline Coronary artery disease & $132(51)$ & $8(40)$ & $11(48)$ & $37(75)$ & .009 \\
\hline Endocarditis & $5(2)$ & $0(0)$ & $2(9)$ & $0(0)$ & .16 \\
\hline Peripheral vascular disease & $41(16)$ & $2(10)$ & $3(13)$ & $10(20)$ & .60 \\
\hline COPD & $41(16)$ & $3(15)$ & $7(29)$ & $12(24)$ & .18 \\
\hline Chronic kidney disease & $51(20)$ & $5(25)$ & $2(9)$ & $13(26)$ & .30 \\
\hline Creatinine clearance, $\mathrm{mL} / \mathrm{min} \pm \mathrm{SD}^{*}$ & $52.4 \pm 19.3$ & $62.7 \pm 23.3$ & $77.5 \pm 27.3$ & $50.1 \pm 22.3$ & $<.001$ \\
\hline NYHA class $\geq$ III/IV & $85(33)$ & $12(60)$ & $14(61)$ & $31(63)$ & .32 \\
\hline LV ejection fraction, $\% \pm \mathrm{SD}$ & $59.8 \pm 9.3$ & $61.5 \pm 5.6$ & $61.7 \pm 6.7$ & $59.4 \pm 6.5$ & .62 \\
\hline Atrial fibrillation & $38(15)$ & $1(5)$ & $2(9)$ & $9(18)$ & .53 \\
\hline Permanent pacemaker & $12(5)$ & $2(10)$ & $0(0)$ & $3(6)$ & .36 \\
\hline Previous cardiac surgery & $19(7)$ & $4(20)$ & $6(26)$ & $6(12)$ & $<.001$ \\
\hline Previous aortic valve surgery & $8(3)$ & $2(10)$ & $6(26)$ & $6(12)$ & $<.001$ \\
\hline Logistic EuroSCORE II, $\% \pm$ SD & $6.5 \pm 5.4$ & $7.0 \pm 10.2$ & $9.2 \pm 4.7$ & $8.9 \pm 8.9$ & .004 \\
\hline
\end{tabular}

Values are number (\%) unless indicated otherwise. SD, Standard deviation; COPD, chronic obstructive pulmonary disease; NYHA, New York Heart Association; $L V$, left ventricular. *Calculated using Cockcroft-Gault formula.

received Sorin Mitroflow valves (Sorin Group), and 33 (13\%) received St Jude Medical Trifecta valves (St Jude Medical, Inc, St Paul, Minn).

In the aortic root enlargement group, 19-mm, 21-mm, and 23-mm prostheses were implanted in 7 (35\%), 12 $(60 \%)$, and $1(5 \%)$ patients, respectively. The 7 patients who received a $19-\mathrm{mm}$ prosthesis initially had a mean aortic annulus of $18 \pm 0.6 \mathrm{~mm}$ that did not fit the 19-valve sizer before the aortic root enlargement. Four patients $(20 \%)$ received Carpentier-Edwards Perimount valves, 15 (75\%) received Carpentier-Edwards Perimount Magna Ease valves, and $1(5 \%)$ received a Sorin Mitroflow valve.

In the stentless group, 19-mm, 21-mm, 23-mm, and 25-mm Freestyle prostheses (Medtronic, Inc, Minneapolis, Minn) were implanted in 1 (4\%), $9(39 \%), 12(53 \%)$, and 1 $(4 \%)$ patients, respectively. All patients in the sutureless group had a Perceval $S$ prosthesis (Sorin Group). Forty-seven $(96 \%)$ patients received small $(19-21 \mathrm{~mm})$ valves and $2(4 \%)$ received medium $(21-23 \mathrm{~mm})$ valves.

CPB and aortic cross-clamp times were significantly shorter in the sutureless group for both isolated AVR and combined procedures. Intraoperative blood loss was also significantly lower in the sutureless group for both isolated AVR and combined procedures.

\section{Perioperative Outcomes}

Clinical outcomes are presented in Table 3. Overall early mortality occurred in $26(7 \%)$ patients $(3 \%$ in the isolated AVR group and $11 \%$ in the combined and redo procedures group). There was a higher incidence of permanent pace maker (PPM) implantation in the sutureless group $(20 \%$; $P=.005)$. In the redo and concomitant procedure group, the incidence of postoperative PPM implantation was significantly higher in the stentless group $(P=.008)$. All PPM implantation in the stentless group occurred with redo procedures. Overall, there was no difference in bleeding requiring reintervention. In the isolated AVR group, there was a higher incidence of reoperation for bleeding $(33 \% ; P=.03)$.

\section{Hemodynamic Data}

Hemodynamic parameters measured preoperatively, intraoperatively, and before discharge are presented in Table 4. There were no differences in preoperative transaortic gradients and aortic valve area among the various groups. Mean aortic annulus diameter, as assessed by intraoperative TEE before incision, was comparable among the groups. However, there was a statistically significant difference in indexed aortic annulus diameter, which ranged between $10.2 \pm 3.8 \mathrm{~mm} / \mathrm{m}^{2}$ in the aortic root enlargement group and $12.1 \pm 1.3 \mathrm{~mm} / \mathrm{m}^{2}$ in the sutureless group $(P=.02)$.

Upon CPB weaning, there was a statistically significant difference in mean transaortic gradients, with the lowest gradients being observed in the stentless group (8.2 $\pm 5.2 \mathrm{~mm} \mathrm{Hg}$ ) (Table 4). There was no case of moderate-to-severe paravalvular leak in this cohort and no statistically significant difference in the incidence of mild paravalvular leak among the various groups. 
TABLE 2. Intraoperative data

\begin{tabular}{|c|c|c|c|c|c|}
\hline Variable & Stented $(\mathbf{n}=259)$ & $\begin{array}{c}\text { Aortic root } \\
\text { enlargement }(n=20)\end{array}$ & Stentless $(\mathbf{n}=\mathbf{2 3})$ & Sutureless $(n=49)$ & $\boldsymbol{P}$ \\
\hline Isolated AVR, $\mathrm{n}(\%)$ & $119(46)$ & $9(46)$ & $9(61)$ & $20(47)$ & .85 \\
\hline \multicolumn{6}{|c|}{ Concomitant procedures, $\mathrm{n}(\%)^{*}$} \\
\hline CABG & $106(38)$ & $9(42)$ & $6(26)$ & $20(41)$ & .54 \\
\hline Multiple valve procedure & $25(11)$ & $1(4)$ & $2(9)$ & $7(14)$ & .70 \\
\hline Septal myectomy & $12(5)$ & $0(0)$ & $3(13)$ & $2(4)$ & .28 \\
\hline Maze & $6(2)$ & $0(0)$ & $0(0)$ & $1(2)$ & $>.99$ \\
\hline \multicolumn{6}{|l|}{ Cross-clamp time, $\min \pm \mathrm{SD}^{\dagger}$} \\
\hline Isolated & $63.7 \pm 23.3$ & $90.7 \pm 27.3$ & $88.9 \pm 21.4$ & $45.9 \pm 20.1$ & $<.001$ \\
\hline Combined/redo procedure & $87.7 \pm 35.5$ & $85.9 \pm 27.9$ & $131.6 \pm 33.0$ & $67.7 \pm 31.3$ & $<.001$ \\
\hline \multicolumn{6}{|l|}{$\mathrm{CPB}$ time, $\min \pm \mathrm{SD} \dagger$} \\
\hline Isolated & $81.2 \pm 29.6$ & $114.1 \pm 30.4$ & $132.7 \pm 56.7$ & $64.1 \pm 29.3$ & $<.001$ \\
\hline Combined/redo procedure & $110.0 \pm 43.2$ & $106.5 \pm 35.2$ & $178.8 \pm 36.8$ & $85.2 \pm 37.4$ & $<.001$ \\
\hline Blood loss, $\mathrm{mL} \pm \mathrm{SD} \dagger$ & & & & & $<.001$ \\
\hline Isolated & $425.2 \pm 322.6$ & $685.6 \pm 458.9$ & $475.0 \pm 128.2$ & $278.8 \pm 192.5$ & .002 \\
\hline Combined/redo procedure & $464.6 \pm 274.9$ & $868.8 \pm 891.6$ & $137.5 \pm 783.2$ & $298.9 \pm 147.9$ & $<.001$ \\
\hline
\end{tabular}

$A V R$, Aortic valve replacement; $C A B G$, coronary artery bypass graft; $S D$, standard deviation; $C P B$, cardiopulmonary bypass. *Categories are not mutually exclusive. $\dagger$ Excluding redo procedures.

Distribution of predischarge TTE transaortic gradients is presented Figure 2. On predischarge TTE evaluation, there was a statistically significant difference in mean transaortic gradients $(P<.001)$ and in aortic iEOA $(P<.001)$. The lowest gradients were in the stentless group $(10.9 \pm 6.2 \mathrm{~mm} \mathrm{Hg})$ and the highest gradients were in the standard AVR group $(18.7 \pm 8.5 \mathrm{~mm} \mathrm{Hg})$. Similarly, the largest aortic iEOA was in the stentless group $\left(1.1 \pm 0.4 \mathrm{~cm}^{2} / \mathrm{m}^{2}\right)$ and the smallest was in the sutureless group $\left(0.79 \pm 0.20 \mathrm{~cm}^{2} / \mathrm{m}^{2}\right)$. No moderate-to-severe paravalvular leak was observed and there was no statistically significant difference in the incidence of mild paravalvular leak. The overall incidence of moderate and severe prosthesis-patient mismatch was $25 \%$ and $14 \%$, respectively, with no statistically significant difference among the groups.

The hemodynamic performance of the various types of stented bioprostheses is summarized in Table 5. The mean body surface area was $1.66 \pm 0.15 \mathrm{~m}^{2}$ in the Perimount group, $1.66 \pm 0.18 \mathrm{~m}^{2}$ in the Magna Ease group, $1.66 \pm 0.15 \mathrm{~m}^{2}$ in the Mitroflow group, and $1.66 \pm 0.13 \mathrm{~m}^{2}$ in the Trifecta group $(P>.99)$. When compared with the other bioprostheses, the Trifecta had lower mean transaortic gradients $(10.3 \pm 3.6 \mathrm{~mm} \mathrm{Hg} ; \quad P<.001)$, larger iEOA $\left(1.00 \pm 0.22 \mathrm{~cm}^{2} / \mathrm{m}^{2} ; P<.001\right)$, and a lower incidence of severe prosthesis-patient mismatch $(0 \% ; P=.01)$.

Dividing the cohort into 2 subgroups of patients with aortic annulus $<20 \mathrm{~mm}$ and $\geq 20 \mathrm{~mm}$ displayed similar results, with the lowest gradients in the stentless groups $(10.4 \pm 6.0 \mathrm{~mm} \mathrm{Hg}$ and $11.6 \pm 6.9 \mathrm{~mm} \mathrm{Hg}$, respectively).

\section{DISCUSSION}

AVR in the context of small aortic annulus is a challenge because residual transaortic gradients and prosthesis-patient mismatch can result in worse clinical outcomes and decreased survival. ${ }^{3}$ The present study is the first to compare contemporary strategies (stented AVR, stentless AVR, sutureless AVR, and AVR with aortic root enlargement) in the management of patients with small aortic annulus (Figure 3).

\section{Stented AVR}

Most patients requiring surgery for aortic stenosis underwent standard stented AVR, because this intervention is straightforward and provides reproducible safe results. In this cohort, patients who received a stented prosthesis displayed the highest residual gradients. Furthermore, $39 \%$ of the patients in the standard AVR group had a postoperative iEOA of $0.85 \mathrm{~cm}^{2} / \mathrm{m}^{2}$ or less. These results are in accordance with the fact that bioprostheses tend to leave supra-physiologic transvalvular systolic gradients. ${ }^{8}$ This could have major long-term impact as several published studies have linked prosthesis-patient mismatch to worse postoperative outcomes in patients undergoing AVR, with less symptomatic relief, less left ventricular mass regression, and higher early and late mortality. ${ }^{3}$

The Trifecta bioprostheses displayed the lowest mean aortic gradient compared with other stented prosthesis $(7.1 \mathrm{~mm} \mathrm{Hg})$ and no severe prosthesis-patient mismatch. This is consistent with other recently published studies in which the Trifecta prosthesis showed near physiologic hemodynamics that mirror the stentless prosthesis., There are no long-term durability data available for the newly introduced Trifecta prosthesis. A few cases of early structural deterioration of the Trifecta prothesis have been reported in the literature. ${ }^{11,12}$ Although this did not discourage the implantation of this valve in our center, 
TABLE 3. Clinical outcomes

\begin{tabular}{|c|c|c|c|c|c|}
\hline Variable & Stented $(\mathbf{n}=259)$ & $\begin{array}{c}\text { Aortic root } \\
\text { enlargement }(n=20)\end{array}$ & Stentless $(\mathbf{n}=\mathbf{2 3})$ & Sutureless $(n=49)$ & $\boldsymbol{P}$ \\
\hline Early mortality & $14(5)$ & $4(20)$ & $3(13)$ & $5(10)$ & .06 \\
\hline Isolated AVR & $2(2)$ & $1(11)$ & $2(22)$ & $0(0)$ & .02 \\
\hline Combined/redo procedure & $12(9)$ & $3(27)$ & $1(7)$ & $5(17)$ & .10 \\
\hline Bleeding requiring reoperation & $21(8)$ & $4(20)$ & $1(4)$ & $3(6)$ & .27 \\
\hline Isolated AVR & $6(5)$ & $3(33)$ & $1(11)$ & $1(5)$ & .03 \\
\hline Combined/redo procedure & $15(11)$ & $1(9)$ & $0(0)$ & $2(7)$ & .68 \\
\hline Stroke & $15(6)$ & $1(5)$ & $1(4)$ & $3(6)$ & $>.99$ \\
\hline Isolated AVR & $5(4)$ & $0(0)$ & $0(0)$ & $0(0)$ & $>.99$ \\
\hline Combined/redo procedure & $10(7)$ & $1(9)$ & $1(7)$ & $3(10)$ & .86 \\
\hline Acute kidney injury* & $89(34)$ & $7(35)$ & $12(52)$ & $17(35)$ & .41 \\
\hline Isolated AVR & $42(35)$ & $3(33)$ & $5(55)$ & $7(35)$ & .66 \\
\hline Combined/redo procedure & $47(34)$ & $4(36)$ & $7(50)$ & $10(34)$ & .69 \\
\hline Renal replacement therapy & $13(5)$ & $1(5)$ & $1(4)$ & $4(8)$ & .90 \\
\hline Isolated AVR & $6(5)$ & $1(11)$ & $0(0)$ & $0(0)$ & .45 \\
\hline Combined/redo procedure & $7(5)$ & $0(0)$ & $1(7)$ & $4(14)$ & .27 \\
\hline Permanent pacemaker implantation & $17(7)$ & $0(0)$ & $4(17)$ & $10(20)$ & .005 \\
\hline Isolated AVR & $7(6)$ & $0(0)$ & $0(0)$ & $3(15)$ & .37 \\
\hline Combined/redo procedure & $10(7)$ & $0(0)$ & $4(29)$ & $7(24)$ & .008 \\
\hline Hospital stay, $\mathrm{d} \pm \mathrm{SD} \dagger$ & $10.0 \pm 7.8$ & $14.5 \pm 26.3$ & $8.5 \pm 4.0$ & $12.3 \pm 9.3$ & .1 \\
\hline Isolated AVR & $9.5 \pm 7.2$ & $16.8 \pm 25.4$ & $7.3 \pm 4.5$ & $13.4 \pm 10.3$ & .04 \\
\hline Combined/redo procedure & $10.6 \pm 10.5$ & $9.7 \pm 4.6$ & $7.6 \pm 4.5$ & $11.5 \pm 9.4$ & .86 \\
\hline
\end{tabular}

Values are number (\%) unless indicated otherwise. AVR, Aortic valve replacement; $S D$, standard deviation. *Defined as an increase in serum creatinine $>50 \%$ from baseline. $\dagger$ Calculated for perioperative survivors only.

further studies with longer follow-up are needed to evaluate its durability. We believe that the Trifecta prosthesis is a rational option for elderly patients with a small aortic annulus who undergo stented AVR.

\section{Aortic Root Enlargement Technique}

Aortic root enlargement has been proposed as an alternative to standard AVR in patients with a small aortic annulus. ${ }^{13}$ The purpose of this procedure is to allow for the implantation of a larger prosthesis. In this group, patients who received a $19-\mathrm{mm}$ stented prosthesis initially had a very small aortic annulus (mean of $18 \mathrm{~mm}$ ) that did not fit the 19-valve sizer before the aortic root enlargement. This could explain the fact that the hemodynamic performance granted by the aortic root enlargement was only slightly superior to that obtained with standard AVR and significantly inferior to that observed in the stentless group. Furthermore, the operative mortality and the incidence of reintervention for bleeding in the aortic root enlargement group was relatively high. According to these results, the role of aortic root enlargement in the management of small aortic annulus remains limited.

\section{Stentless AVR}

Our study suggests that stentless and Trifecta prostheses have the best hemodynamic performance in terms of postoperative transaortic gradients and iEOA. The advantage of complete aortic root replacement is the capacity to oversize the prosthesis in relation to the patient's aortic annulus. In our study, most patients $(57 \%)$ received a 23-mm or larger prosthesis. Two randomized trials have demonstrated lower gradients than stented bioprosthesis in patients with a small aortic annulus. ${ }^{14,15}$ The use of this prosthesis is also associated with left ventricular mass regression and a more complete resolution of left ventricular hypertrophy compared with stented valves. ${ }^{14}$ Recent reports have demonstrated good durability up to 15 years after implantation and superior midterm survival when compared with the stented prosthesis. ${ }^{16,17}$

This procedure is technically more complex, requiring advanced experience in aortic surgery, and results in a longer operative time, raising questions about its widespread applicability. ${ }^{18}$ The operative mortality in the stentless group was relatively high. The stentless AVR cohort being small, any conclusion on increased operative mortality remains speculative. However, previous reports raised the potential of increased adverse perioperative outcomes ${ }^{19,20}$ with the use of stentless AVR. Furthermore, the high PPM implantation rate in patients undergoing stentless AVR has been described by other groups ${ }^{21,22}$ and may be, at least in our study, partly explained by the high proportion of patients in this group undergoing redo surgery. The implantation of a stentless bioprosthesis should be considered in low-risk, relatively younger patients undergoing AVR because it provides the best hemodynamic performance. 
TABLE 4. Hemodynamic parameters

\begin{tabular}{|c|c|c|c|c|c|}
\hline Variable & Stented $(n=259)$ & $\begin{array}{c}\text { Aortic root } \\
\text { enlargement }(n=20)\end{array}$ & Stentless $(\mathbf{n}=\mathbf{2 3})$ & Sutureless $(n=49)$ & $\boldsymbol{P}$ \\
\hline \multicolumn{6}{|l|}{ Preoperative TTE } \\
\hline Peak transaortic gradient, mm Hg & $77.5 \pm 32.3$ & $61.4 \pm 22.9$ & $84.3 \pm 32.9$ & $77.2 \pm 30.5$ & .22 \\
\hline Mean transaortic gradient, $\mathrm{mm} \mathrm{Hg}$ & $48.9 \pm 20.6$ & $44.1 \pm 18.6$ & $51.9 \pm 23.5$ & $46.8 \pm 20.1$ & .60 \\
\hline AVA, $\mathrm{cm}^{2}$ & $0.74 \pm 0.25$ & $0.80 \pm 0.21$ & $0.76 \pm 0.32$ & $0.74 \pm 0.22$ & .82 \\
\hline Indexed AVA, $\mathrm{cm}^{2} / \mathrm{m}^{2}$ & $0.40 \pm 0.20$ & $0.42 \pm 0.19$ & $0.44 \pm 0.21$ & $0.45 \pm 0.16$ & .45 \\
\hline \multicolumn{6}{|l|}{ Intraoperative TEE before $\mathrm{CPB}$} \\
\hline Annulus diameter, mm & $19.7 \pm 1.2$ & $19.1 \pm 1.7$ & $19.0 \pm 1.7$ & $19.5 \pm 1.3$ & .10 \\
\hline Indexed annulus diameter, $\mathrm{mm} / \mathrm{m}^{2}$ & $11.5 \pm 2.4$ & $10.2 \pm 3.8$ & $11.2 \pm 1.5$ & $12.1 \pm 1.3$ & .02 \\
\hline \multicolumn{6}{|l|}{ Intraoperative TEE after $\mathrm{CPB}$ weaning } \\
\hline $\begin{array}{l}\text { Mean transaortic gradient, } \mathrm{mm} \mathrm{Hg} \\
\text { Paravalvular leak, } \mathrm{n}(\%)\end{array}$ & $11.1 \pm 6.8$ & $10.5 \pm 6.2$ & $8.2 \pm 5.2$ & $9.0 \pm 4.4$ & .04 \\
\hline None & 247 (95) & $20(100)$ & $23(100)$ & $45(92)$ & .44 \\
\hline Trivial-mild & $12(5)$ & $0(0)$ & $0(0)$ & $4(8)$ & \\
\hline Moderate-severe & $0(0)$ & $0(0)$ & $0(0)$ & $0(0)$ & \\
\hline \multicolumn{6}{|l|}{ Predischarge TTE } \\
\hline Peak transaortic gradient, mm $\mathrm{Hg}$ & $33.6 \pm 14.7$ & $29.4 \pm 14.5$ & $20.3 \pm 10.4$ & $29.8 \pm 9.7$ & $<.001$ \\
\hline Mean transaortic gradient, $\mathrm{mm} \mathrm{Hg}$ & $18.7 \pm 8.5$ & $16.2 \pm 7.3$ & $10.9 \pm 6.2$ & $17.3 \pm 6.7$ & $<.001$ \\
\hline $\begin{array}{l}\text { Mean transaortic gradient per indexed } \\
\text { annulus diameter, } \mathrm{mm} \mathrm{Hg} / \mathrm{mm} / \mathrm{m}^{2}\end{array}$ & $1.6 \pm 0.7$ & $1.5 \pm 0.8$ & $1.0 \pm 0.6$ & $1.5 \pm 0.6$ & .004 \\
\hline $\mathrm{EOA}, \mathrm{cm}^{2}$ & $1.42 \pm 0.38$ & $1.61 \pm 0.47$ & $1.82 \pm 0.53$ & $1.26 \pm 0.27$ & .001 \\
\hline Indexed EOA, $\mathrm{cm}^{2} / \mathrm{m}^{2}$ & $0.82 \pm 0.24$ & $0.86 \pm 0.37$ & $1.10 \pm 0.36$ & $0.79 \pm 0.20$ & .01 \\
\hline \multicolumn{6}{|l|}{ Paravalvular leak, n (\%) } \\
\hline None & $241(93)$ & $19(95)$ & $22(96)$ & $40(82)$ & .08 \\
\hline Trivial-mild & $18(7)$ & $1(5)$ & $1(4)$ & $9(18)$ & \\
\hline Moderate-severe & $0(0)$ & $0(0)$ & $0(0)$ & $0(0)$ & \\
\hline Severe PP mismatch* & $37(14)$ & $1(5)$ & $2(9)$ & $10(20)$ & .38 \\
\hline Moderate PP mismatch $\dagger$ & $63(24)$ & $6(30)$ & $4(17)$ & $14(29)$ & .71 \\
\hline
\end{tabular}

\section{Sutureless Bioprosthesis}

In our study, sutureless AVR displays similar hemodynamic performance to standard AVR in the context of small aortic annulus. In a recently published multicenter propensity-matched analysis, D'Onofrio and colleagues ${ }^{23}$ suggested that sutureless AVR compares favorably with

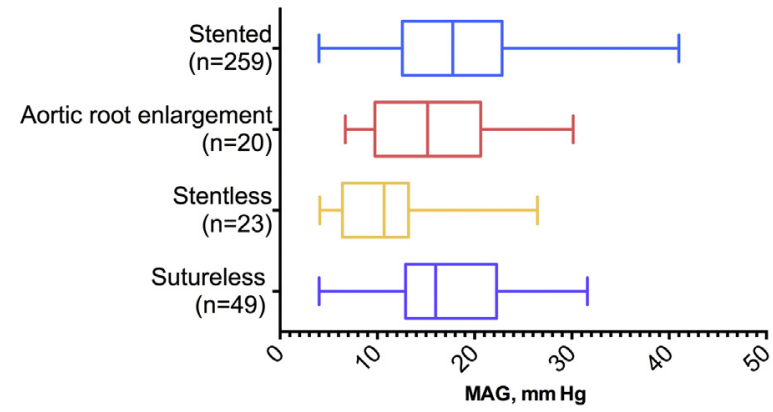

FIGURE 2. Box-and-whiskers graph of postoperative mean gradients by procedure type, assessed with transthoracic echocardiography. Vertical line represents the median. Left and right extremities of each box represent the first and third quartiles, respectively. The whiskers extend to the lowest and highest observations. MAG, Mean aortic gradient. standard AVR and transcatheter aortic valve implantation (TAVI) in terms of perioperative outcomes and early postoperative gradients. In addition, Shrestha and colleagues $^{6}$ compared hemodynamic performance of sutureless and stented prosthesis in the context of small aortic annulus $(<22 \mathrm{~mm})$. There was no difference in terms of postoperative gradients and EOA. The mean transaortic gradient in the sutureless group was close to our sutureless cohort $(15.9 \mathrm{~mm} \mathrm{Hg})$. In contrast, in a multicenter study, Villa and colleagues $^{24}$ compared 276 patients who underwent sutureless AVR with the Perceval S prosthesis with a small versus a large prosthesis. There was no difference in terms of postoperative gradients suggesting that sutureless AVR in the context of small aortic annulus could result in comparable hemodynamic performance in both small and large aortic annulus. Sutureless AVR in patients with small aortic annulus is safe in terms of early postoperative hemodynamic results. Although postoperative paravalvular leakage remains an important concern for surgeons while using sutureless valves, there were no patients with moderate or severe paravalvular leakage at discharge in this study. 
TABLE 5. Hemodynamic parameters in stended prosthesis

\begin{tabular}{|c|c|c|c|c|c|}
\hline Variable & Perimount $(\mathbf{n}=\mathbf{5 8})$ & Magna Ease $(n=145)$ & Mitroflow $(n=23)$ & Trifecta $(\mathbf{n}=33)$ & $\boldsymbol{P}$ \\
\hline \multicolumn{6}{|l|}{ Intraoperative $\mathrm{TEE}$ before $\mathrm{CPB}$} \\
\hline Annulus diameter, $\mathrm{mm} \pm \mathrm{SD}$ & $19.7 \pm 1.4$ & $19.7 \pm 1.2$ & $19.2 \pm 1.3$ & $19.7 \pm 1.2$ & .23 \\
\hline Indexed annulus diameter, $\mathrm{mm} / \mathrm{m}^{2} \pm \mathrm{SD}$ & $10.9 \pm 3.2$ & $11.7 \pm 2.5$ & $11.5 \pm 1.2$ & $11.7 \pm 1.1$ & .17 \\
\hline \multicolumn{6}{|l|}{ Intraoperative TEE after CPB weaning } \\
\hline Mean transaortic gradient $(\mathrm{mm} \mathrm{Hg})$ & $13.2 \pm 7.9$ & $11.3 \pm 6.9$ & $12.0 \pm 6.1$ & $7.1 \pm 3.3$ & .001 \\
\hline \multicolumn{6}{|l|}{ Predischarge TTE } \\
\hline Peak transaortic gradient, $\mathrm{mm} \mathrm{Hg} \pm \mathrm{SD}$ & $41.6 \pm 18.2$ & $35.3 \pm 11.4$ & $41.4 \pm 14.4$ & $17.9 \pm 6.1$ & $<.001$ \\
\hline Mean transaortic gradient, $\mathrm{mm} \mathrm{Hg} \pm \mathrm{SD}$ & $22.3 \pm 8.0$ & $19.9 \pm 8.5$ & $19.4 \pm 8.1$ & $10.3 \pm 3.6$ & $<.001$ \\
\hline $\mathrm{EOA}, \mathrm{cm}^{2} \pm \mathrm{SD}$ & $1.20 \pm 0.34$ & $1.34 \pm 0.35$ & $1.22 \pm 0.49$ & $1.62 \pm 0.37$ & $<.001$ \\
\hline Indexed EOA, $\mathrm{cm}^{2} / \mathrm{m}^{2} \pm \mathrm{SD}$ & $0.73 \pm 0.21$ & $0.81 \pm 0.23$ & $0.74 \pm 0.31$ & $1.00 \pm 0.22$ & $<.001$ \\
\hline Severe PP mismatch, $\mathrm{n}(\%)^{*}$ & $7(12)$ & $23(16)$ & $6(26)$ & $0(0)$ & .01 \\
\hline Moderate PP mismatch, $\mathrm{n}(\%) \dagger$ & $14(24)$ & $34(23)$ & $2(9)$ & $9(27)$ & .36 \\
\hline
\end{tabular}

$T E E$, Transesophageal echocardiogram; $C P B$, cardiopulmonary bypass; $S D$, standard deviation; $T T E$, transthoracic echocardiogram; EOA, effective orifice area; $P P$, prosthesispatient. *Defined as an indexed aortic effective orifice area $<0.60 \mathrm{~cm}^{2} / \mathrm{m}^{2}$. $\dagger$ Defined as an indexed aortic effective orifice area between 0.60 and $0.85 \mathrm{~cm} / \mathrm{m}^{2}$.

Despite patients in the sutureless group being older and presenting a higher logistic EuroSCORE, no excess operative mortality was observed. However, patients in this group had the highest rate of atrioventricular block
(30\%) and PPM implantation (20\%). Due to the absence of a sewing ring, the Perceval $\mathrm{S}$ prosthesis relies on radial forces for stability, raising concerns that this may cause compression of the conduction system. This mechanism

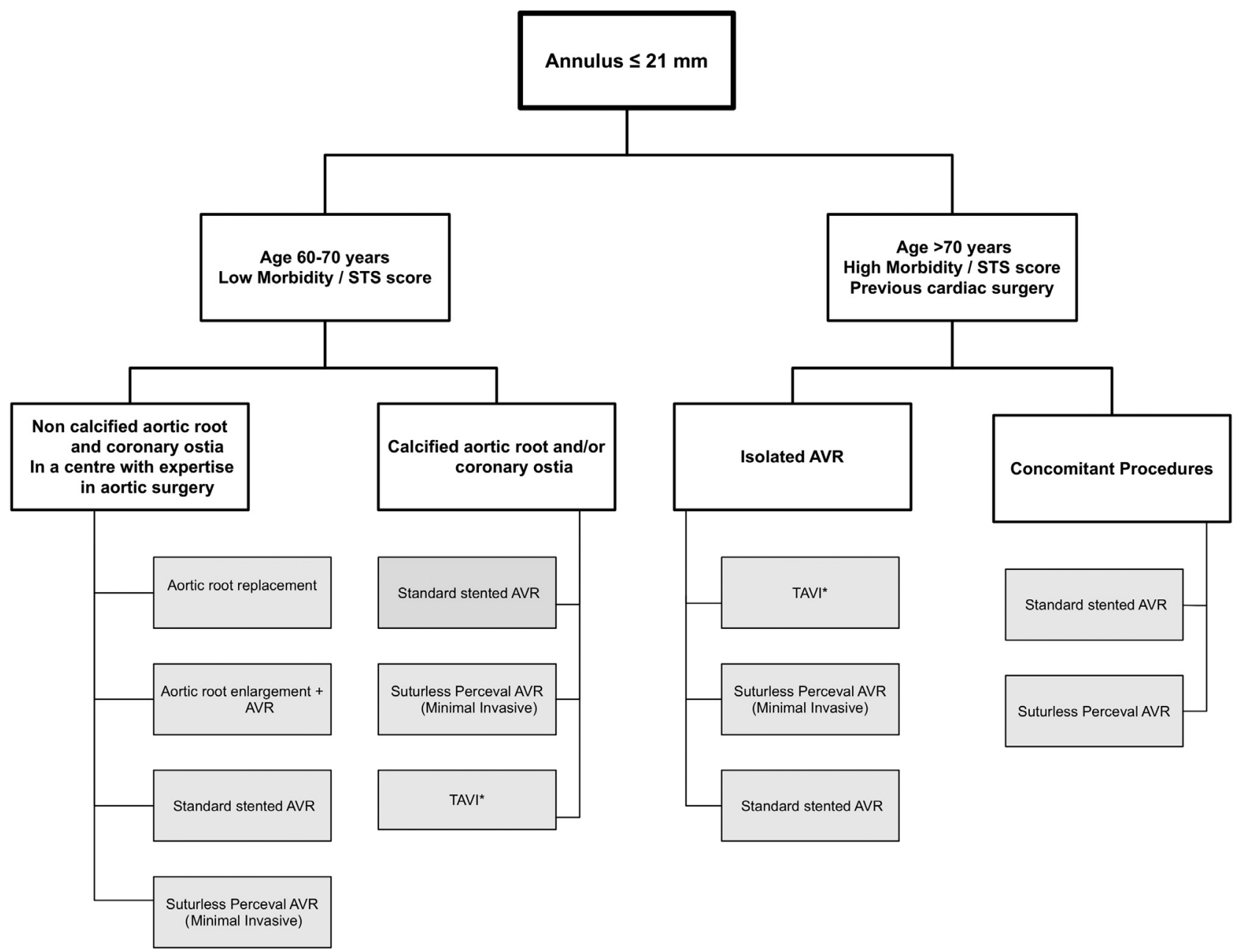

FIGURE 3. Proposed algorithm for management of small aortic annulus. *TAVI (transcatheter aortic valve implantation) was not assessed by the present study. STS, Society of Thoracic Surgeons; AVR, aortic valve replacement. 
could explain the increased incidence of conduction abnormalities in these patients. The long hospital stay observed in the sutureless AVR group can be explained by the high rate of pacemaker implantation in this group, an intervention that generally necessitates additional hospitalization days.

Although there was no statistically significant difference in the incidence of severe prosthesis-patient mismatch among the 4 groups $(P=.38)$, there was a trend toward higher rates in the sutureless group. One of the specificities of sutureless AVR is that surgeons are not obliged to totally decalcify the aortic annulus after excision of the diseased aortic cusps. In our center, patients with severe calcification of the aortic annulus and/or the aortic root underwent the minimum necessary decalcification of the aortic annulus followed by deployment of the sutureless aortic valve. We think that this might partly explain the high incidence of prosthesis-patient mismatch in this group. Nonetheless, this hypothesis remains entirely speculative and is not based on any hard evidence.

\section{Study Limitations}

The main limitations of this study include its retrospective nature, lack of follow-up data, and the relatively small number of patients in the aortic root enlargement and stentless groups in comparison with the standard stented AVR and sutureless groups. Thus, the study sample size limits the conclusions that can be drawn from the present study. In addition, early complications in each group should be interpreted with caution because the observed differences could be due to differences in the baseline characteristics of the populations, which cannot be fully accounted for. Furthermore, the choice of procedure was sometimes dictated by anatomic limitations. For example, in the setting of a calcified aortic root and/or calcified coronary buttons, aortic root enlargement or aortic root replacement were seldom performed. In such a context, we favored simpler operations such as stented bioprosthetic AVR or sutureless AVR. Nonetheless, this is the first study to compare these 4 techniques and provides valuable hemodynamic information that adds to the current body of literature in the management of the small aortic annulus. Our study did not include patients who underwent TAVI. Percutaneous options represent an interesting alternative to surgical AVR in intermediate and high-risk patients, especially in the setting of a small aortic annulus. ${ }^{25}$ Further studies are required to evaluate the hemodynamic performance of TAVI in this context compared with the 4 surgical strategies reported in the present study.

\section{CONCLUSIONS}

Management of the small aortic annulus should be tailored. Stentless and Trifecta prostheses seem to produce the best hemodynamic outcomes. However, stentless prostheses were associated with longer CPB times, relatively higher early mortality, and perioperative morbidity. In our cohort, the remaining 3 options provided similar hemodynamic performance with relatively better perioperative outcomes. The most recent device, the Perceval sutureless prosthesis, is a safe alternative with a hemodynamic performance that appears to be in the same range as stented valves and aortic root enlargement procedures. Further studies are needed to compare the long-term durability of these techniques and to ascertain that superior perioperative hemodynamic performance improves long-term clinical outcomes.

\section{Conflict of Interest Statement}

Denis Bouchard discloses that he has received proctorship and lecturer fees from Sorin and Edwards Canada. Philippe Demers discloses that he has received proctorship from Sorin Canada. All other authors have nothing to disclose with regard to commercial support.

\section{References}

1. Carabello BA, Paulus WJ. Aortic stenosis. Lancet. 2009;373:956-66.

2. Nishimura RA, Otto CM, Bonow RO, Carabello BA, Erwin JP III, Guyton RA, et al. 2014 AHA/ACC Guideline for the Management of Patients With Valvular Heart Disease: Executive Summary: A Report of the American College of Cardiology/American Heart Association Task Force on Practice Guidelines. Circulation. 2014;129:2440-92.

3. Pibarot P, Weissman NJ, Stewart WJ, Hahn RT, Lindman BR, McAndrew T, et al. Incidence and sequelae of prosthesis-patient mismatch in transcatheter versus surgical valve replacement in high-risk patients with severe aortic stenosis: a PARTNER trial cohort-an analysis. J Am Coll Cardiol. 2014;64:1323-34.

4. Yoganathan AP, Woo YR, Sung HW, Williams FP, Franch RH, Jones M. In vitro hemodynamic characteristics of tissue bioprostheses in the aortic position. J Thorac Cardiovasc Surg. 1986;92:198-209.

5. Cohn LH. Comparison of bioprostheses in patients with small aortic annulus. J Am Coll Cardiol. 2006;47:1088.

6. Shrestha M, Maeding I, Hoeffler K, Koigeldiyev N, Marsch G, Siemeni T, et al. Aortic valve replacement in geriatric patients with small aortic roots: are sutureless valves the future? Interact Cardiovasc Thorac Surg. 2013;17:778-82.

7. Akins CW, Miller DC, Turina MI, Kouchoukos NT, Blackstone EH, Grunkemeier GL, et al. Guidelines for reporting mortality and morbidity after cardiac valve interventions. Ann Thorac Surg. 2008;85:1490-5.

8. Fries R, Wendler O, Schieffer H, Schafers HJ. Comparative rest and exercise hemodynamics of 23-mm stentless versus 23-mm stented aortic bioprostheses. Ann Thorac Surg. 2000;69:817-22.

9. Bavaria JE, Desai ND, Cheung A, Petracek MR, Groh MA, Borger MA, et al. The St Jude Medical Trifecta aortic pericardial valve: results from a global, multicenter, prospective clinical study. J Thorac Cardiovasc Surg. 2014;147:590-7.

10. Tasca G, Redaelli P, Riva B, De Carlini CC, Lobiati E, Gamba A. Hemodynamic comparison between Trifecta and freestyle aortic valve during exercise in patients with small aortic root. J Card Surg. 2015;30:400-4.

11. Saxena P, Greason KL, Schaff HV. Early structural valve deterioration of the Trifecta aortic valve biological prosthesis: a word of caution. J Thorac Cardiovasc Surg. 2014;147:e10-1

12. Campisi S, Camilleri L, Innorta A, Azarnoush K. Early failures of Trifecta aortic bioprosthesis. J Thorac Cardiovasc Surg. 2014;148:e133-4.

13. Manouguian S, Seybold-Epting W. Patch enlargement of the aortic valve ring by extending the aortic incision into the anterior mitral leaflet. New operative technique. J Thorac Cardiovasc Surg. 1979;78:402-12.

14. Ali A, Halstead JC, Cafferty F, Sharples L, Rose F, Coulden R, et al. Are stentless valves superior to modern stented valves? A prospective randomized trial. $\mathrm{Circu}$ lation. 2006;114:I535-40.

15. Narang S, Satsangi DK, Banerjee A, Geelani MA. Stentless valves versus stented bioprostheses at the aortic position: midterm results. J Thorac Cardiovasc Surg. 2008;136:943-7. 
16. Bach DS, Kon ND. Long-term clinical outcomes 15 years after aortic valve replacement with the Freestyle stentless aortic bioprosthesis. Ann Thorac Surg. 2014;97:544-51.

17. Luciani GB, Casali G, Auriemma S, Santini F, Mazzucco A. Survival after stentless and stented xenograft aortic valve replacement: a concurrent, controlled trial. Ann Thorac Surg. 2002;74:1443-9.

18. Borger MA, Lehmann S, Seeburger J, Mohr FW. The demise of the stentless valve. Semin Thorac Cardiovasc Surg. 2012;24:5-7.

19. Bach DS, Cartier PC, Kon ND, Johnson KG, Deeb GM, Doty DB, et al. Impact of implant technique following freestyle stentless aortic valve replacement. Ann Thorac Surg. 2002;74:1107-13; discussion 1113-4.

20. Borger MA, Prasongsukarn K, Armstrong S, Feindel CM, David TE. Stentless aortic valve reoperations: a surgical challenge. Ann Thorac Surg. 2007;84: 737-43; discussion 743-4

21. El-Hamamsy I, Clark L, Stevens LM, Sarang Z, Melina G, Takkenberg JJ, et al. Late outcomes following freestyle versus homograft aortic root replacement: results from a prospective randomized trial. J Am Coll Cardiol. 2010; $55: 368-76$.
22. Song Z, Lehr EJ, Wang S. An alternative subcoronary implantation technique decreases the risk of complete heart block after stentless aortic valve replacement. J Cardiovasc Dis Res. 2012;3:46-51.

23. D'Onofrio A, Rizzoli G, Messina A, Alfieri O, Lorusso R, Salizzoni S, et al. Conventional surgery, sutureless valves, and transapical aortic valve replacement: what is the best option for patients with aortic valve stenosis? A multicenter, propensity-matched analysis. J Thorac Cardiovasc Surg. 2013;146:1065-70; discussion 1070-1.

24. Villa E, Messina A, Laborde F, Shrestha M, Troise G, Zannis K, et al. Challenge for perceval: aortic valve replacement with small sutureless valves-a multicenter study. Ann Thorac Surg. 2015;99:1248-54.

25. Kalavrouziotis D, Rodes-Cabau J, Bagur R, Doyle D, De Larochelliere R, Pibarot $\mathrm{P}$, et al. Transcatheter aortic valve implantation in patients with severe aortic stenosis and small aortic annulus. J Am Coll Cardiol. 2011:58:1016-24.

Key Words: aortic valve replacement, aortic annulus, stentless prostheses, sutureless prostheses, prothesis-patient mismatch

\title{
EDITORIAL COMMENTARY
}

\section{Every millimeter counts}

\author{
Hans-Hinrich Sievers, MD, and Michael Scharfschwerdt, PhD
}

\footnotetext{
From the Department of Cardiac and Thoracic Vascular Surgery, University Hospital of Schleswig-Holstein, Campus Lübeck, Lübeck, Germany.

Disclosures: Authors have nothing to disclose with regard to commercial support.

Received for publication July 1, 2016; accepted for publication July 1, 2016; available ahead of print Aug 18, 2016.

Address for reprints: Hans-Hinrich Sievers, MD, University of Lübeck, Department of Cardiac and Thoracic Vascular Surgery, Ratzeburger Allee 160, 23538 Lübeck, Germany (E-mail: Hans-Hinrich.Sievers@uksh.de). J Thorac Cardiovasc Surg 2016;152:1028-9 $0022-5223 / \$ 36.00$

Copyright (c) 2016 by The American Association for Thoracic Surgery http://dx.doi.org/10.1016/j.jtcvs.2016.07.035
}

We enjoyed reading the article Ghoneim and colleagues ${ }^{1}$ in this issue of the Journal, "Management of Small Aortic Annulus in the Era of Sutureless Valves: A Comparative Study Between Different Biological Options," because it addresses important issues of our daily praxis. Ghoneim and colleagues ${ }^{1}$ investigated different biologic substitutes in small aortic annuli and found that the Trifecta (St Jude Medical, Inc, St Paul, Minn) and stentless valves provided the most effective relieve of aortic stenosis. Although there is a lot of bias in comparing the different groups, the results reflect real-life conditions, showing pressure gradients that are much higher than normal. Because bioprostheses are implanted more and more in younger patients, a pressure gradient as low as possible is important not only for survival but also for degeneration of the tissue. . $^{2,3}$ The annulus after decalcification is the implantation area to start with. The use of this plane determines the efficiency of surgery and the

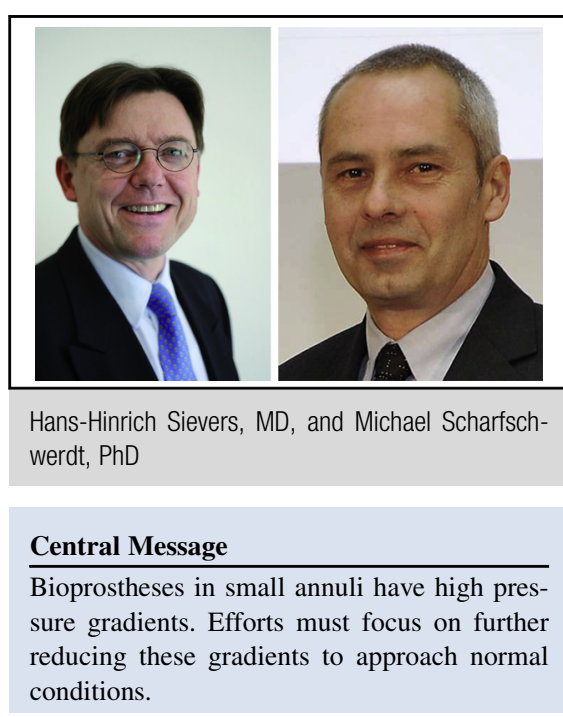

See Article page 1019

bioprosthesis. Ideally, the minimal geometric orifice area of the substitute should be the same size as the implantation area. For example, a given aortic annular diameter of $20 \mathrm{~mm}$ means an area of $3.14 \mathrm{~cm}^{2}$. If the achieved geometric orifice area of the substitute is only $18 \mathrm{~mm}$ (1 $\mathrm{mm}$ at each side for mounting device), the geometric orifice area would be $2.54 \mathrm{~cm}^{2}$, which is nearly 